\title{
Jobs deficits, neighbourhood effects, and ethnic penalties: the geography of ethnic-labour-market inequality
}

\author{
Ludi Simpson, Kingsley Purdam \\ Cathie Marsh Centre for Census and Survey Research, University of Manchester, Oxford Road, \\ Manchester M13 9PL, England; \\ e-mail: ludi.simpson@manchester.ac.uk, kingsley.purdam@manchester.ac.uk
}

\section{Abdelouahid Tajar}

Arthritis Research Unit, University of Manchester, Oxford Road, Manchester M13 9PL, England; e-mail: abdelouahid.tajar@manchester.ac.uk

\section{John Pritchard, Danny Dorling}

Social and Spatial Inequalities Research Group, University of Sheffield, Winter Street,

Sheffield S10 2TN, England; e-mail: j.pritchard@sheffield.ac.uk, danny.dorling@sheffield.ac.uk

Received 21 September 2007; in revised form 20 February 2008; published online 18 December 2008

\begin{abstract}
The reduction of inequalities in the labour market both between ethnic groups and between local areas indicates improved access to jobs because a diverse workforce is socially and economically desirable. We construct and analyse a unique evidence base of the labour-market circumstances at the neighbourhood level. We use the 2001 Census data for England and Wales to examine the impact of age, sex, birthplace, and educational qualifications on the employment of ethnic minorities nationally. We compute locally expected employment on the basis of these relationships and local characteristics, and compare it with locally observed employment. Our analysis demonstrates that 1.1 million new jobs are required to bring every ethnic group in every locality up to the average England and Wales employment rate. National ethnic-group differences account for most of this local job deficit; local variation in demographic composition and human capital account for a smaller proportion of the jobs deficit. Residual neighbourhood effects have both a geography common to each ethnic group (for example, a gradient of higher jobs deficits in the Midlands, the North of England, and Wales), and some group-specific characteristics (for example, more favourable outcomes for Pakistani and Bangladeshi groups in the North than might have been expected). The findings and approach allow targeting employment policies geographically and thematically. In addition, the on-line evidence base (http://asp.ccsr.ac.uk/dwp) is a public resource which can be used to investigate local outcomes and to prioritise remedial action.
\end{abstract}

\section{Introduction}

Labour-market inequalities between ethnic groups and between areas are a priority focus for governments whose intention is to reduce the social disadvantage which those inequalities may represent. Evidence shows that inequalities between ethnic groups persist and the ethnic minorities face unfair disadvantage and discrimination in the labour market (Berthoud, 2000; Cabinet Office, 2003; Dale et al, 2002; Esmail and Everington, 1997; Heath and Cheung, 2006; Modood et al, 1997).

We provide a separate assessment of the effects on local employment outcomes of ethnic group, demographic and human capital composition, and the size of the remaining differences between neighbourhoods. We estimate the neighbourhood ethnic penalty by comparing the local number of people in employment with that expected if national employment rates for each age, sex, birthplace, and qualification group are applied locally. Shortfalls in local employment are jobs deficits which are used to judge the relevant importance of ethnicity and place. To the extent that ethnic-minority employment shortfalls are replicated in all neighbourhoods, issues of equality are of continued policy importance in all types of area. However, different geographies of jobs deficit imply specific problems requiring policy initiatives sensitive to local and to 
group circumstances and preferences. These issues motivate our analyses, and the policy implications of our findings are discussed in the final section. In the remainder of this introduction we set out the rationale for the measures of ethnic penalties, neighbourhood effects, and jobs deficits used in the paper.

Average inequalities between populations or areas are the result of a variety of societal and personal investments in training, provision of jobs, success in turning qualifications into employment, and the impact of demographic composition such as age structure and birthplace, reviewed for Great Britain by Heath and Yu (2005). Raw differences between populations can be seen as the cumulative impact of disadvantages, including but not limited to discrimination in the labour market. The raw differences between groups are an important indicator of social cleavages. Many social scientists attempt to quantify the extent to which raw differences between groups can be identified with specific factors that create them (Berthoud, 2000; Borjas, 1995; Cheung and Heath, 2005; Heath and McMahon, 1997).

Demographic composition and human capital are the two factors that past studies consistently identify as influences on labour-market outcomes. If a population is particularly young then a relatively large proportion will be studying rather than working; a high proportion born overseas might on average suggest inexperience and lack of confidence in the labour market. Such demographic compositional factors are not easy to change, although their impact may be ameliorated for example by provision of English classes for those whose first language is not English. Human capital-principally the skills an individual brings to the labour market - is also known to have a major impact on success in the labour market. Generally, the greater an individual's qualifications, the more likely he or she is to gain a job and to remain economically active [Heath and McMahon (1997) show this for England and Wales in 1991, as we do in this paper for 2001]. Thus, the extent to which ethnic minorities have gained qualifications may account for some of the labour-market inequalities found between ethnic groups. That component of inequalities can be targeted with resources to improve and equalise the educational opportunities of each population. While educational qualifications are the most important aspect of human capital's influence on labour-market success, the census data source excludes other aspects such as the skills and experience gained while in employment.

The evidence in Britain suggests that at least one half of the average differences in labour-market outcomes for ethnic groups can be attributed to their composition, such that those with lower outcomes are on average younger and have fewer qualifications or have other individual circumstances that disadvantage them (Carmichael and Woods, 2000; Leslie et al, 2001). The remaining differences are often termed 'ethnic penalties'.

The database described and used in this paper measures ethnic penalties nationally and for each neighbourhood of England and Wales (we occasionally use the shorthand 'national' to refer to England and Wales). The evidence shows whether a local outcome that is different from the national is consistent with local demographic composition and human capital. The part of local outcomes which is not consistent with local composition can be thought of as a neighbourhood ethnic penalty and is termed a 'neighbourhood effect'. It indicates local factors that create a worse or better outcome than would be expected from the usual impact of demography and human capital. The nature of these local factors remains hidden, but the identification of areas and ethnic groups where such factors are having an impact is a means of targeting and prioritising the need for investigation and remedial measures. Durlauf (2004) reviews the concepts and varied approaches to analysis of neighbourhood effects. Here, we are concerned not with the mechanisms by which neighbourhood effects operate, but with estimating 
the size of their impact relative to the impacts of ethnic penalties and individual characteristics that operate across all areas of residence. Clark and Drinkwater (2002) examine neighbourhood effects for ethnic minorities in Britain from data for the early 1990s and find they are similar to those for the white-majority population, across different levels of neighbourhood ethnic concentration.

We begin with examples of the raw neighbourhood labour-market outcomes which motivate the analyses of this paper. Data estimation methods for the evidence base and jobs deficits are specified in a section on data and methods. We then describe the influence on employment rates of age, sex, qualifications, and country of birth for each ethnic group defined in the census, using data for England and Wales as a whole. These patterns are used to account for variation in local outcomes that are consistent with local demographic composition and human capital. Local jobs deficits are estimated in the following section, taking into account neighbourhood composition in order to derive the remaining neighbourhood effects. The geographical pattern of these neighbourhood effects is compared across ethnic groups through measures of correlation and regional values. The interpretation of neighbourhood effects and their potential use in policy making and the targeting of resources are addressed in the final summary and discussion section.

\section{National and local labour-market outcomes: examples}

Table 1 shows the employment rate for each of the sixteen ethnic groups recorded in the census, for England and Wales and for three contrasting neighbourhoods within the UK. The precise definitions of variables and neighbourhoods are discussed in the next section; here, the table is used to clarify the data and research questions. The ethnic groups are sorted in table 1 in decreasing order of employment rate for

Table 1. Ethnic-group employment rates (\%): England and Wales, and three contrasting neighbourhood (source: 2001 Census).

\begin{tabular}{lllll}
\hline & $\begin{array}{l}\text { England and } \\
\text { Wales }\end{array}$ & Sparkbrook & $\begin{array}{l}\text { Middlesbrough } \\
\text { East }\end{array}$ & $\begin{array}{l}\text { Reading } \\
\text { North East }\end{array}$ \\
\hline White Briton & 75 & 55 & 49 & 84 \\
Irish & 70 & 48 & 33 & 83 \\
Other white & 67 & 40 & 27 & 73 \\
Caribbean & 66 & 55 & 52 & 78 \\
Indian & 66 & 48 & 56 & 78 \\
Asian white & 61 & 38 & 46 & 72 \\
Other mixed & 60 & 45 & 36 & 72 \\
Other Asian & 59 & 34 & 28 & 68 \\
Other black & 58 & 42 & 25 & 67 \\
Chinese & 58 & 49 & 48 & 79 \\
Caribbean white & 58 & 41 & 56 & 62 \\
African white & 57 & 24 & 47 & 67 \\
African & 57 & 39 & 37 & 57 \\
Other & 53 & 37 & 38 & 58 \\
Pakistani & 43 & 32 & 48 & 71 \\
Bangladeshi & 40 & 33 & 48 & 82 \\
All groups & 73 & 40 & & 79
\end{tabular}

Notes. Percentages based on a population under 50 are italicised.

Sparkbrook: Sparkbrook and Small Heath wards; Middlesbrough East: Beckfield, Beechwood, Clairville, Gresham, North Ormesby and Brambles Farm, Middlehaven, Pallister, Thorntree, and University wards; Reading North East: Caversham, Mapledurham, Peppard, Thames, Bulmershe and Whitegates, Loddon, and South Lake wards. 
England and Wales. The white-Briton population is the only group with a higher employment rate than the average $73.1 \%$ for England and Wales. The other white groups (Irish, and other white) have higher employment rates than nonwhite and mixed groups. The lowest employment rates-Pakistani and Bangladeshi groups at $42.7 \%$ and $39.5 \%$, respectively-reflect the particularly low employment rates of women in these two groups and of Muslim women in Britain in general (Dale et al, forthcoming).

Sparkbrook in Birmingham in central England has the lowest employment rate in England and Wales and is an ethnically diverse area where white Britons are a minority of the population. Middlesbrough East, on the north-east coast of England, has the lowest employment rate among neighbourhoods with an above-average proportion of white Britons. Reading North East, in a prosperous part of the Thames Valley, has the highest employment rate among neighbourhoods with a proportion of white-Briton residents below the average. Every ethnic group in each of the two low-employment neighbourhoods has lower employment rates than any of the ethnic groups in Reading North East. It seems clear that Reading North East has advantages in employmentor attracts individuals with advantages. To afford to live in an area such as Reading North East often requires at least one, and more usually two or more, household members in receipt of relatively high earnings. Low employment concentrated in a neighbourhood may be partly a selection effect, such that those with low incomes are concentrated in areas of relatively cheap housing (Fieldhouse and Tranmer, 2001).

Inequality between ethnic groups is apparent in each of the neighbourhoods, such that the white-Briton group has higher rates of employment and the Pakistani and Bangladeshi groups have lower rates than each neighbourhood's overall employment rate. If there are clear neighbourhood differences then there is also an independent impact of ethnic group within each neighbourhood. However, the patterns of inequalities between groups are not exactly those of England and Wales as a whole. Bangladeshis have relatively high employment rates in Middlesbrough East and Reading North East, while the Irish group's employment is particularly low in Middlesbrough East. Some of these different patterns may be attributable to the local sociodemographic composition of each group, which we go on to explore below.

One complicating factor lies in the differing sizes of the populations. What weight should one put on the relatively high employment rate of Bangladeshis in both Middlesbrough East and Reading North East, given that it is based on fewer than thirty residents in each case? Our focus on the 'jobs deficit' is robust to the many small local minority populations, by using the number of people affected by low employment rates. Small populations receive correspondingly small weight.

\section{Methods and data for measuring neighbourhood effects and job deficits}

In this section we describe the data used to measure employment and to define neighbourhoods. We develop the calculation of an expected employment by relating neighbourhood composition to national analysis of the main determinants of employment. Neighbourhood effects and jobs deficits are defined by comparing observed with expected employment. The procedure yields a national database available for further research, documented in Simpson et al (2006) and CCSR (2006).

The 'employment rate' measures participation in paid work, whether as an employee or self-employed, as a proportion of the whole population. It has become a favoured measure of participation in the UK and is often reported in parallel with the more traditional economic activity rate, which includes the unemployed in the numerator (Simpson et al, 2006). In the 2001 UK Census, the employment rate for males and females is identified separately for those aged 16-24 and for older adults up to the 
age of 74 , for each ethnic group. The employment rate is defined in this paper as all those in work expressed as a percentage of the adult population, excluding those retired. ${ }^{(1)}$ Students studying full time and working are included as employed in the census outputs and in all the analyses reported here.

We have defined 1138 'labour-market neighbourhoods' with a population of around $30000-50000$ in England and Wales, as defined and used in Thomas and Dorling (2007). These neighbourhoods are more relevant to local policy interventions than larger areas such as whole city regions, but are large enough to distinguish towns and major parts of cities. The neighbourhoods are each an amalgamation of wards represented in the 2001 Census and are designed to have similar population size. They distinguish, for example, Peckham from other parts of the Borough of Southwark, and twenty neighbourhoods within the Birmingham local authority district (including Sparkbrook, in table 1). The neighbourhoods have also been used in the UK by the Neighbourhood Renewal Unit within the Office of the Deputy Prime Minister for neighbourhood analysis and by the Department of Work and Pensions (Parkinson et al, 2006; Simpson et al, 2006). Analysis at a smaller scale with electoral wards gave similar results.

The impact of demographic composition and human capital on employment rates is well documented (Cheung and Heath, 2005; Clark and Drinkwater, 2007; Heath and Yu, 2005; Simpson et al, 2006). These analyses show consistently higher employment rates for men, for those with qualifications and particularly those with higher education, and for people over the age of 24 . The precise relationships between employment, age, sex, and birthplace vary between ethnic groups, with particularly low employment amongst Pakistani and Bangladeshi women, and relatively high employment amongst Caribbean women. For each ethnic group, the beneficial effect of qualifications on employment rates is diminished for those born outside the UK. This will partly be because qualifications gained outside the UK may have been recorded but carry less weight in the UK labour market. It is also the case that those born abroad include pioneer labour migrants whose employment on arrival was guaranteed at a time of shortages for unskilled and unqualified labour.

Local areas with fewer young or older people, with more men, or with more qualified people, and in particular areas with a combination of these characteristics, would be expected to have higher employment rates. For example, an area of established family housing might be expected to have more middle-aged people and with qualifications, and therefore be likely to have a relatively high employment rate. Conversely, an inner-city area with many young people is likely to have a relatively low employment rate.

Neighbourhood effects are computed by comparing local employment with the employment rate expected locally, given this evidence for England and Wales as a whole. The comparison is based on the employment rates for England and Wales for every category combination of the five variables: ethnic group, age, sex, qualifications, and country of birth, derived from a table specially commissioned from the 2001

(1) The census output includes all those aged up to 74, including many retired people who are not usually included in labour-market analyses. Many nonwhite groups have few elderly at present. Thus, the retired are excluded to avoid falsely depressing the employment rate of the older white groups. We have used the full sixteen published categories of ethnic group including four categories of mixed and a subdivision of the white category, in which we relabel the category 'white - British' as 'white Britons' to emphasise that the census has asked for a 'cultural background' and to avoid all connotations of nationality which is not asked in the UK Census. White Britons are $83 \%$ of the England and Wales population. We tend not to interpret the residual categories (other white, other black, other Asian, and other), because their composition in each case is an unknown mixture of those who, for a variety of reasons, did not find the specific census categories helpful. This heterogeneity creates neighbourhood variation as illustrated later in the paper. 
Census. They are applied to each neighbourhood's composition according to the same five variables. The result is the expected number employed in the neighbourhood based on its local mix of age, sex, qualifications, birthplace, and ethnic group. ${ }^{(2)}$

Algebra is useful to specify the calculations. Capital letters are used for counts of people, and lower-case letters for rates. The subscript $i$ denotes the subpopulation categories for which the expectation is calculated in each locality $l$. In the most detailed case, $i$ refers to the full cross-classification of age, sex, qualifications, birthplace, and ethnic group. Summing over the subpopulation categories gives the expected employment in the locality:

$$
E_{l}^{\mathrm{exp}}=\sum_{i} e_{\mathrm{N}, i}^{\mathrm{obs}} P_{l, i}^{\mathrm{obs}},
$$

where obs and exp refer to observed and expected values, respectively, $E$ represents employment, $e$ the employment rate, $P$ the population denominator, and $\mathrm{N}$ refers to England and Wales. The expected employment rate in locality $l$ is then:

$$
e_{l}^{\exp }=\frac{E_{l}^{\exp }}{P_{l}^{\text {obs }}}
$$

where the denominator is summed over the same subpopulation categories $i$ as the expected employment. The approach is the same as direct standardisation to a reference population in demography.

The full on-line evidence base includes the observed and expected rates for five different labour-market indicators: employment, unemployment, economic activity, economic inactivity, and part-time work, each disaggregated not only by locality and ethnic group but also by age and sex (CCSR, 2006). Tables of observed and expected rates for user-selected aggregates of localities are provided interactively by summing observed and expected values across localities. When the neighbourhood observed rate is lower than would be expected from the neighbourhood composition, something other than the usual effects of age, sex, qualifications, and birthplace has influenced the local outcome.

We focus on one of the five outcomes-employment-and on the aggregated neighbourhood effect for all persons of an ethnic group, without distinction of age or sex. We focus not on the difference between observed and expected rates but on the local jobs deficit, the difference between the observed and expected numbers of employed when the observed employment is lower than the expected employment:

$$
J_{l}= \begin{cases}E_{l}^{\mathrm{exp}}-E_{l}^{\mathrm{obs}}=P_{l}^{\mathrm{obs}}\left(e_{l}^{\exp }-e_{l}^{\mathrm{obs}}\right), & \text { if } \mathrm{E}_{1}^{\exp }>\mathrm{E}_{1}^{\mathrm{obs}}, \\ 0, & \text { otherwise. }\end{cases}
$$

The expression illustrates that the local jobs deficit $J_{l}$ gives weight to both low observed employment rates and the numbers affected. Focus on the local jobs deficit avoids distraction by the many neighbourhoods where extreme employment rates result from small ethnic-group populations. To provide a simple example, if the expected employment rate is the value for England and Wales as a whole $\left(e_{l}^{\exp }=73 \%\right)$, in a neighbourhood population of 100 people of working age $\left(P_{l}^{\text {obs }}\right)$ the observed employment rate is $63 \%\left(e_{l}^{\text {obs }}\right)$, and the deficit is 10 jobs. The same low employment

(2) The fully detailed neighbourhood composition is unknown. Census outputs provide only two variable local marginal distributions for each ethnic group. The full local disaggregation of five variables necessary to apply the national employment rates was estimated from these marginal tables using iterative proportional fitting. This is a relatively complex five-dimensional implementation of a general estimation procedure described by Bishop et al (1975) and Simpson and Tranmer (2005), and applied here as described in Simpson (2006). The expected local employment is the product of the England and Wales employment rates and the local denominators. 
rate in a bigger neighbourhood population of 1000 gives a jobs deficit of 100 . The jobs deficit indicates the local lack of jobs as an excess over an expected value. If the employment rate indicates a buoyant economy, a jobs deficit indicates a depressed economy. The deficit may be summed across neighbourhoods; the cumulated deficit across these two example neighbourhoods is 110 jobs.

The detail of the subpopulation categories $i$ determines the extent to which local composition is taken into account when computing the expected employment. It is the detail of the model on which local expectations are based. In the example of the previous paragraph, no detail is included, so that the local expectation is simply the overall England and Wales employment rate. In this paper, this crude expectation is supplemented by two others: (a) ethnic-group categories, where the expected local employment for each group is that group's employment rate for England and Wales, and (b) the local composition for each group of age, sex, birthplace, and qualifications, where the expected local employment is based on the employment rate for England and Wales for each of these subpopulation categories. We now compare these expectations with neighbourhood observed outcomes, to derive the residual neighbourhood effects.

\section{Neighbourhood differences}

We begin this section with examples of neighbourhood profiles which enable a comparison of the local employment rate for a specific ethnic group with the national and local rates both for that ethnic group and for other ethnic groups, and with the employment rate expected from the demographic composition and aggregate educational qualifications of the neighbourhood.

We then cumulate the local jobs deficit across all of England and Wales, thereby summarising the impact of ethnic group, the impact of the local composition, and the remaining neighbourhood variation that must be related to other characteristics.

Figure 1 shows the employment profiles for Sparkbrook, Middlesbrough East, and Reading North East. The 'national' and 'locally observed' employment rates are taken from table 1, while the 'locally expected' rate has been computed as described, using the fully disaggregated England and Wales rates applied to each neighbourhood subpopulation of ethnic group, age, sex, qualifications, and birthplace.

(a)

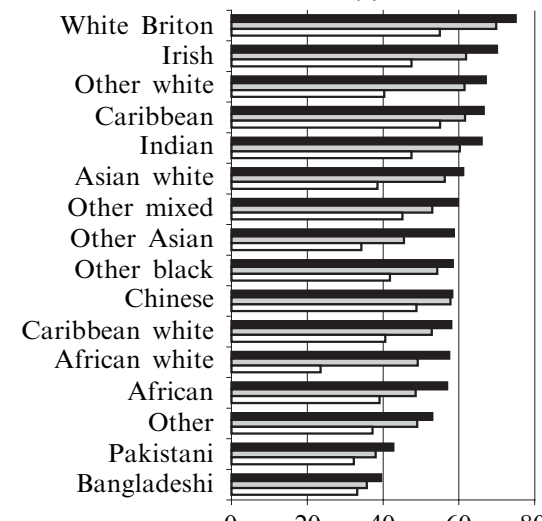

(b)

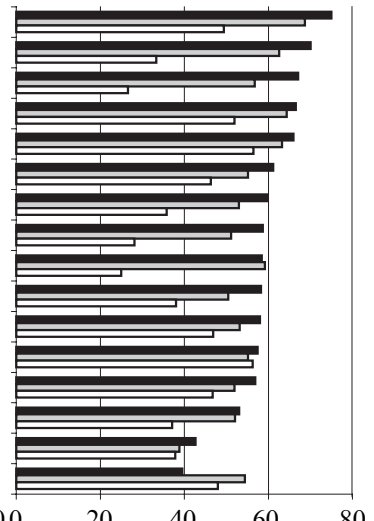

(c)

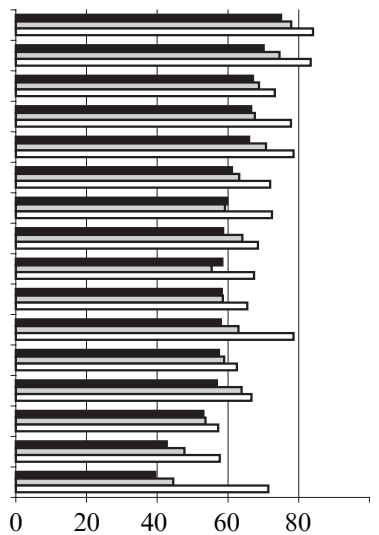

- National

$\square$ Locally expected

$\square$ Locally observed

Figure 1. Neighbourhood employment rates: observed rate, locally expected rate, and national rate for (a) Sparkbrook; (b) Middlesborough East; (c) Reading North East. 
In Sparkbrook, the locally expected employment rate for every ethnic group is below the national average. The local lack of human capital and younger demographic structure prompts us not to expect as high employment rates as in other neighbourhoods. However, for every ethnic group the observed employment rate is lower still, often by ten percentage points or more. There is a clear neighbourhood effect depressing employment rates for each ethnic group, though not to the same extent for each group.

Middlesbrough East displays a similar pattern but illustrates how taking into account local composition can put the observed differences between ethnic groups into context. For the three white groups the neighbourhood effect is larger than in Sparkbrook, depressing the employment rate by around twenty percentage points beyond those expected from the local qualification levels and demographic composition. The nonwhite ethnic groups, which are smaller in this neighbourhood, show a more mixed pattern. The local Bangladeshi group is expected to have an employment rate considerably higher than its national rate-principally because there are relatively few young people and women in this small local population. The observed employment rate which is higher than many other groups in the neighbourhood is in fact lower than the expected value for Bangladeshis given their composition. The advantage of neighbourhood analysis within the national context is shown here in two ways. In Middlesbrough the Bangladeshi population is older and more qualified than nationally, and this has raised their employment rate. However, the labour-market 'performance' of the Bangladeshi population associated with their advantageous composition is not as high as nationally. The analysis identifies employment that is lower than expected, and local knowledge can be sought to understand and remedy the difference.

In contrast, every ethnic group in Reading North East has a higher employment rate than expected from its composition. There is a positive neighbourhood effect, over and above the positive impact of the age, sex, qualifications, and birthplace of the individuals who live there. To some extent, the extra neighbourhood effect may be one of further self-selection, since most residents will need stable employment in order to afford the higher cost of living in this area.

\section{Job deficits}

Table 2 cumulates the jobs deficit across all neighbourhoods of England and Wales. The individual neighbourhood effects illustrated in figure 1 are summed. This gives weight to all neighbourhoods where the employment rate is low, and gives larger weight to larger populations. The ethnic groups are again sorted by decreasing employment rate in England and Wales. The jobs deficit is calculated first relative to a crude expectation that every group in each area might have the overall England and Wales employment rate of $73.1 \%$. The jobs deficit is the number of jobs that need to be filled to bring up to the England and Wales average all those neighbourhood populations with employment below $73.1 \%$. Expressed in this way, in total there is a deficit of over 1.1 million jobs. The greatest impact (in terms of population number) of low local employment rates is on the white-Briton population itself. Although on average this group has higher employment rates, there are many neighbourhoods where the employment rate of white Britons is significantly below the average, and those neighbourhoods have relatively large white-Briton populations. Such neighbourhoods include many poor exindustrial areas including Middlesbrough East, and Liverpool's Riverside. Half the total jobs deficit is among white Britons.

If the white-Briton jobs deficit is large in absolute terms, what of its size relative to its population of working age? The jobs deficit for white Britons is $2 \%$, well below the equivalent figure for minority-ethnic groups. The smaller ethnic-minority populations 
Table 2. Cumulated local jobs deficit, when local employment is less than reference.

\begin{tabular}{|c|c|c|c|c|c|c|c|}
\hline \multirow[t]{2}{*}{ Ethnic group } & \multirow[t]{2}{*}{$\begin{array}{l}\text { Population of } \\
\text { working age }\end{array}$} & \multicolumn{2}{|c|}{$\begin{array}{l}\text { Expectation: England } \\
\text { and Wales rate, } 73.1 \%\end{array}$} & \multicolumn{2}{|c|}{$\begin{array}{l}\text { Expectation: England and } \\
\text { Wales ethnic-group rate }\end{array}$} & \multicolumn{2}{|c|}{$\begin{array}{l}\text { Expectation: based on local qualifications } \\
\text { and demographic composition }\end{array}$} \\
\hline & & $\begin{array}{l}\text { jobs } \\
\text { deficit }\end{array}$ & $\begin{array}{l}\text { percentage of } \\
\text { population } \\
\text { of working age }\end{array}$ & $\begin{array}{l}\text { jobs } \\
\text { deficit }\end{array}$ & $\begin{array}{l}\text { percentage of } \\
\text { population } \\
\text { of working age }\end{array}$ & $\begin{array}{l}\text { jobs } \\
\text { deficit }\end{array}$ & $\begin{array}{l}\text { percentage of } \\
\text { population } \\
\text { of working age }\end{array}$ \\
\hline White Briton & 28130382 & 567558 & 2.0 & 760966 & 2.7 & 579190 & 2.1 \\
\hline Irish & 436137 & 23075 & 5.3 & 16341 & 3.7 & 13131 & 3.0 \\
\hline Other white & 1011288 & 71508 & 7.1 & 38275 & 3.8 & 31216 & 3.1 \\
\hline Caribbean & 384617 & 29816 & 7.8 & 14005 & 3.6 & 11183 & 2.9 \\
\hline Indian & 723855 & 56371 & 7.8 & 25982 & 3.6 & 16647 & 2.3 \\
\hline Asian white & 92473 & 12150 & 13.1 & 4661 & 5.0 & 3920 & 4.2 \\
\hline Other mixed & 81226 & 11617 & 14.3 & 3992 & 4.9 & 3558 & 4.4 \\
\hline Other Asian & 171443 & 26109 & 15.2 & 8391 & 4.9 & 6566 & 3.8 \\
\hline Other black & 56124 & 8925 & 15.9 & 2565 & 4.6 & 2323 & 4.1 \\
\hline Chinese & 170085 & 26892 & 15.8 & 10539 & 6.2 & 6646 & 3.9 \\
\hline Caribbean white & 94782 & 15073 & 15.9 & 4266 & 4.5 & 3791 & 4.0 \\
\hline African white & 41096 & 7159 & 17.4 & 2465 & 6.0 & 2282 & 5.6 \\
\hline African & 323006 & 53259 & 16.5 & 10747 & 3.3 & 7786 & 2.4 \\
\hline Other & 170376 & 34786 & 20.4 & 8040 & 4.7 & 7120 & 4.2 \\
\hline Pakistani & 436459 & 133302 & 30.5 & 14775 & 3.4 & 8322 & 1.9 \\
\hline Bangladeshi & 163402 & 55318 & 33.9 & 6195 & 3.8 & 4246 & 2.6 \\
\hline Total & 32486751 & 1132918 & 3.5 & 932205 & 2.9 & 707928 & 2.2 \\
\hline Nonwhite groups & 2908944 & 470776 & 16.2 & 116623 & 4.0 & 84391 & 2.9 \\
\hline
\end{tabular}


are affected by low employment to a greater intensity than the majority white-Briton group. The jobs deficit reaches over 30\% for the Pakistani and Bangladeshi populations. This total local jobs deficit for each ethnic group as a percentage of their population follows the pattern of employment rates in table 1.

The England and Wales average employment rate is the target used at present by the UK government's Department for Work and Pensions. One might argue that the current white-Briton group rate should be the reference in order to emphasise the gap between privileged and other groups. In this case, jobs deficits appear whenever the local population group employment rate is below $75.0 \%$, and the cumulated jobs deficit across England and Wales is raised to 1.4 million (not shown in the table).

Within each ethnic group, there are also wide variations between neighbourhood employment rates. Table 2 also shows the jobs deficit when each neighbourhood's ethnic-group population is compared with that ethnic group's own national rate. Apart from the white-Briton group; the jobs deficits are lower than when compared with the overall national rate, but are not insignificant. For example, overall, more than sixteen thousand jobs would be needed to bring Irish employment in each neighbourhood up to the current Irish average. In statistical terms it is natural that, in about half of all neighbourhoods, the employment rate will be below the average. The cumulated jobs deficit measures by how much these neighbourhoods are below the average. As a percentage of their population of working age, the Chinese group has the largest jobs deficit at $6.2 \%$ and there is more variation in Chinese employment between neighbourhoods than for other groups. The percentage jobs deficit is least for white Britons and the variation in their employment rates is less than for other groups.

Some of the variation in employment rates between neighbourhoods is due to local demographic composition and human capital. Thus, the final column measures the extent of remaining neighbourhood effects for each ethnic group, which are explained neither by the group's own national employment rates nor by the group's local neighbourhood composition of age, sex, qualifications, and birthplace. The Chinese, Pakistani, and Indian group neighbourhood differences are accounted for by local composition in this way more than other groups. The Pakistani residual jobs deficit due to neighbourhood effects $(1.9 \%)$ is smaller than that for white Britons, while the jobs deficits is 3\% or greater for the Chinese and Irish groups, and for each of the mixed and other groups. The mixed and other groups are very diverse, containing subgroups with high and low employment rates who tend to live in different areas which are therefore identified by neighbourhood effects.

The residual neighbourhood effect of between $2 \%$ and $3 \%$ for most ethnic groups is small compared with the jobs deficits of between $10 \%$ and $30 \%$ for the Chinese, African, Pakistani, and Bangladeshi groups. This suggests that neighbourhood effects are not as great as ethnic inequalities. Demographic composition and qualifications do have some impact on neighbourhood inequalities. This is shown by the last columns in table 2. However, the impact is relatively small. It is always less than $2.5 \%$ of the population of working age and is always smaller than both the ethnic inequalities and the remaining neighbourhood effects. In other words, differences in human capital are important but account for only a small amount of the wide disparity found in the local employment rates of ethnic groups.

\section{Correlation between ethnic groups' neighbourhood effects}

Finally, we examine the geographical variation in neighbourhood effects. First, we consider the relationship between jobs deficits for whites and for other groups and whether the areas of greatest scarcity are the same. Table 3 shows this in two ways. 
Table 3. Correlation between employment neighbourhood effects of white-Briton and other ethnic groups.

Percentage of group's local jobs deficits where there is also a white-Briton deficit
Pearson correlation between group and white-Briton jobs deficit

\begin{tabular}{lll}
\hline Irish & 86 & 0.81 \\
Other white & 87 & 0.79 \\
Caribbean white & 79 & 0.57 \\
African white & 82 & 0.47 \\
Asian white & 74 & 0.58 \\
Other mixed & 80 & 0.58 \\
Indian & 83 & 0.65 \\
Pakistani & 84 & 0.51 \\
Bangladeshi & 93 & 0.42 \\
Other Asian & 86 & 0.63 \\
Caribbean & 91 & 0.65 \\
African & 88 & 0.50 \\
Other black & 88 & 0.46 \\
Chinese & 81 & 0.62 \\
Other & 81 & 0.56
\end{tabular}

Notes: 1138 neighbourhoods of England and Wales; 'neighbourhood effect': observed-expected local employment rate; each neighbourhood is weighted by the population of working age in the ethnic group shown.

The neighbourhoods are weighted by the minority-ethnic-group population to avoid the influence of volatile rates caused by the many small neighbourhood minority-ethnic populations. There is a high coincidence of ethnic-group geographies of low employment. Of the neighbourhoods in which a group has a jobs deficit, the percentage that also have a white-Briton jobs deficit is high, always above $70 \%$ and often nearer $90 \%$.

The size of the jobs deficits is considered in the second column of table 3 by the correlation between neighbourhood effects for the white-Briton group with each other group. The neighbourhood effect is measured here as the locally expected employment rate subtracted from the locally observed employment rate, for each of the 1138 neighbourhoods in England and Wales. The correlations are all above 0.45. This suggests that, while the influences are not precisely the same for each group, there is a strong common geography to neighbourhood employment variation. It is particularly similar for the three white groups. The Bangladeshi, African, and Pakistani groups' geography is the least correlated with the white-Briton geography of neighbourhood effects (correlations of between 0.46 and 0.51), suggesting that these groups' local fortunes are influenced by factors that do not influence the white groups. These populations represent the three most recent streams of migration to Britain, whose inclusion in the labour market is least secure. The ethnic minorities with the longest history in Britain are most integrated in its labour-market geography, in the sense of having the most similar job profile to the white majority.

Regional jobs deficits also show a common pattern, with differences evident amongst the most recent immigrant-origin groups. When the total jobs deficit for all ethnic groups is summed, there is a clear regional gradient from low jobs deficit in the South and East of England, to highest job deficits in the North and in Wales, with London and the Midlands in an intermediate position. Table 4 shows this gradient most clearly in (b), where the jobs deficit is expressed as a percentage of the group's population of working age. The regional gradient from South to North and to Wales 
Table 4. Cumulated local jobs deficit by region.

\begin{tabular}{|c|c|c|c|c|c|c|c|c|c|}
\hline & White Briton & Irish & Caribbean & Indian & Chinese & African & Pakistani & Bangladeshi & Total \\
\hline \multicolumn{10}{|l|}{ (a) Jobs deficit } \\
\hline East of England & 12505 & 319 & 168 & 401 & 528 & 278 & 172 & 94 & 17607 \\
\hline South East & 26004 & 668 & 413 & 758 & 508 & 349 & 210 & 47 & 33960 \\
\hline South West & 26255 & 416 & 204 & 322 & 245 & 173 & 74 & 35 & 29698 \\
\hline East Midlands & 33219 & 575 & 593 & 1280 & 568 & 386 & 275 & 57 & 40015 \\
\hline West Midlands & 34734 & 1564 & 1693 & 2520 & 950 & 607 & 2906 & 508 & 51673 \\
\hline London & 60040 & 4624 & 6478 & 4840 & 1708 & 3983 & 1502 & 2968 & 108228 \\
\hline Yorkshire & 62086 & 659 & 462 & 1791 & 601 & 567 & 2001 & 180 & 74054 \\
\hline North West & 132382 & 2765 & 939 & 3874 & 1133 & 900 & 978 & 235 & 150554 \\
\hline Wales & 102030 & 1045 & 146 & 436 & 130 & 315 & 132 & 53 & 106938 \\
\hline North East & 89934 & 498 & 87 & 426 & 274 & 227 & 73 & 71 & 95201 \\
\hline Total & 579190 & 13131 & 11183 & 16647 & 6646 & 7786 & 8322 & 4246 & 707928 \\
\hline \multicolumn{10}{|c|}{ (b) Percentage of working age population } \\
\hline East of England & 0.4 & 0.8 & 0.9 & 1.1 & 3.5 & 2.2 & 0.7 & 0.9 & 0.5 \\
\hline South East & 0.6 & 1.2 & 2.0 & 1.2 & 2.0 & 1.9 & 0.6 & 0.5 & 0.7 \\
\hline South West & 0.9 & 2.0 & 2.3 & 2.7 & 2.6 & 3.8 & 1.7 & 1.2 & 1.0 \\
\hline East Midlands & 1.4 & 2.5 & 3.2 & 1.5 & 5.9 & 5.5 & 1.6 & 1.4 & 1.5 \\
\hline West Midlands & 1.2 & 3.5 & 3.1 & 2.1 & 7.9 & 7.0 & 3.2 & 2.9 & 1.6 \\
\hline London & 2.2 & 2.9 & 2.8 & 1.6 & 2.8 & 1.6 & 1.6 & 3.3 & 2.3 \\
\hline Yorkshire & 2.2 & 3.0 & 3.1 & 5.0 & 6.4 & 8.2 & 2.3 & 2.6 & 2.4 \\
\hline North West & 3.5 & 5.4 & 6.7 & 7.9 & 5.9 & 8.1 & 1.4 & 1.6 & 3.6 \\
\hline Wales & 6.0 & 9.1 & 7.8 & 7.3 & 2.9 & 13.1 & 2.6 & 1.7 & 6.0 \\
\hline North East & 6.0 & 8.6 & 11.4 & 5.8 & 6.2 & 11.8 & 0.8 & 2.1 & 6.1 \\
\hline Total & 2.1 & 3.0 & 2.9 & 2.3 & 3.9 & 2.4 & 1.9 & 2.6 & 2.2 \\
\hline
\end{tabular}


is repeated for the white-Briton, Irish, Caribbean, and Indian groups but is different for the other groups.

The Pakistani and Bangladeshi groups in Wales and the North are not as disadvantaged as in the Midlands and in London. One must remember that this notion of disadvantage is in relation to each group's national employment rates. Pakistani and Bangladeshi employment rates are low in all regions, although less so in Wales and the North. The local jobs deficit amongst the Chinese is noticeably higher than that of other groups in the South and East of England and in the West Midlands, but not so high in Wales as most other groups. Neighbourhoods of significantly low Chinese employment occur in most regions. The jobs deficit at the neighbourhood level for Indians is highest in the North West.

Three quarters of African residents of working age in England and Wales live in London [Simpson et al (2006, page 42) provide a regional population summary]. It is therefore not surprising that the largest cumulated local jobs deficit is in London. However, this is the lowest jobs deficit as a proportion of population of all the regions. Africans outside London tend to have considerably lower employment rates than in London, lower than their demographic characteristics and human capital would suggest. The jobs deficit is particularly high in the West Midlands and the North of England. This may relate to groups of African individuals and families who are particularly isolated and unsupported in the labour market.

Identification of the largest neighbourhood effects can inform policy development and the targeting of resources to tackle inequalities. In table 5 for each of the eight 'main' groups, the five greatest neighbourhood jobs deficits are listed, calculated as the number of jobs required to bring the group's neighbourhood employment up to the England and Wales average of 73.1\%. Middlesbrough East and Sparkbrook both feature in the list, for the white and Pakistani groups. Only four neighbourhoods appear on the list for more than one group, and these are in diverse areas of London and Birmingham. The largest jobs deficits are usually in neighbourhoods which have high unemployment and where the group has greatest presence; these will logically not be the same neighbourhood for each group. Our analysis at this level allows policy makers to target the large jobs deficits where the approach for remedial actions may be nuanced according to the different cultural, political, and employment contexts.

Table 5(b) shows the neighbourhood effect-the jobs deficit calculated given that group's national employment rates and the local demographic composition and human capital. The figures are therefore smaller than the raw jobs deficits and particularly so for the groups whose national employment rates are much lower than the England and Wales average. These residual jobs deficits do not show the number of jobs needed to equalise the employment rates between groups, but the number of jobs needed to bring the group up merely to the employment level expected locally for that group, given the local demographic composition and human capital. In fact, these two measures of disadvantage often coincide, with overall unemployment and group unemployment as benchmarks. Four out of the five same neighbourhoods occur in both parts of the table for all but three groups. What lies behind these three groups' unique unemployment geography? For the Indian group, the two largest residual jobs deficits are in Batley and Blackburn East, which are the only neighbourhoods where more than $90 \%$ of the Indian population is Muslim. For the Chinese group, three London neighbourhoods with large raw jobs deficits may include many young students, as they do not appear in the largest residual deficits after age and other composition are taken into account.

Demographic composition and human capital are associated with the raw jobs deficits amongst Africans, so that the residual jobs deficits highlight other neighbourhoods. These other differences may be related to different country or social origins 
Table 5. Neighbourhoods with greatest jobs deficits for each ethnic group.

\begin{tabular}{|c|c|c|c|c|c|c|c|}
\hline White Briton & Irish & Caribbean & Indian & Chinese & African & Pakistani & Bangladeshi \\
\hline \multicolumn{8}{|c|}{ (a) Relative to the England and Wales employment rate of $73.1 \%$} \\
\hline 6850 & 446 & 933 & 2555 & 636 & 1102 & 6934 & 5955 \\
\hline Middlesbrough & London: & London: & Leicester: & Cambridge & London: & Bradford & London: \\
\hline East & Tollington & Hackney South & Knighton & West & Tottenham North & University & Poplar \\
\hline 6460 & 389 & 908 & 2298 & 464 & 1014 & 6764 & 5593 \\
\hline Liverpool: & London: & Birmingham: & Leicester: & Manchester: & London: & Birmingham: & London: \\
\hline Riverside North & Holborn & Ladywood West & Belgrave & Moss Side & Hackney South & Sparkbrook & Stepney \\
\hline 6433 & 385 & 882 & 2134 & 439 & 957 & 3710 & 3852 \\
\hline Liverpool: & Manchester: & Birmingham: & Blackburn & London: & London: & Bradford: & London: \\
\hline Riverside South & Gorton West & Ladywood East & East & Hyde Park & Forest Gate & Undercliffe & Bow \\
\hline 6321 & 358 & 873 & 1571 & 409 & 847 & 3657 & 1705 \\
\hline Knowlsley & London: & London: & Birmingham: & London: & London: & Birmingham: & Oldham \\
\hline North & St Pancras & Vauxhall South & Handsworth & Southwark North & Vauxhall North & Ladywood East & West \\
\hline 5369 & 306 & 671 & 1400 & 406 & 843 & 3445 & 1581 \\
\hline Leeds: & Manchester: & London: & London: & London: & London: & Birmingham: & London: \\
\hline Headingley & Ardwick & Vauxhall North & Southall West & Holborn & East Ham South & Fox Hollies & East Ham North \\
\hline \multicolumn{8}{|c|}{ (b) Relative to local expectation for the group } \\
\hline 6127 & 348 & 460 & 894 & 274 & 226 & 954 & 803 \\
\hline Liverpool: & London: & London: & Blackburn & Cambridge & London: & Birmingham: & London: \\
\hline Riverside South & Holborn & Hackney South & East & West & Southall West & Sparkbrook & Poplar \\
\hline 5556 & 289 & 425 & 514 & 188 & 225 & 784 & 803 \\
\hline Middlesbrough & London: & Birmingham: & Batley & Manchester: & London: & Bradford & London: \\
\hline East & Tollington & Ladywood West & & Moss Side & Holborn & University & Stepney \\
\hline 5526 & 275 & 410 & 509 & 184 & 223 & 469 & 463 \\
\hline Liverpool: & London: & London: & Leicester: & Sheffield: & London: & Bradford: & London: \\
\hline Riverside North & St Pancras & Vauxhall South & Knighton & City West & Regent's Park & Undercliffe & Bow \\
\hline 5218 & 247 & 386 & 476 & 164 & 207 & 425 & 161 \\
\hline Cambridge & Manchester: & Birmingham: & Bolton: & Liverpool: & London: & Birmingham: & Birmingham: \\
\hline West & Gorton West & Ladwood East & Daubhill & Riverside North & East Ham North & Ladywood East & Ladywood East \\
\hline 5013 & 231 & 310 & 456 & 161 & 202 & 306 & 110 \\
\hline Leeds: & London: & London: & London: & London: & London: & Birmingham: & London: \\
\hline Headingley & Regent's Park & Stoke Newington & East Ham North & Deptford North & St Pancras & Fox Hollies & East Ham North \\
\hline
\end{tabular}


within Africa, different residence status, or may relate to a range of local policies and community responses to the labour market, a discussion of which is included in the next and final part of the paper.

\section{Summary and discussion}

The empirical starting point of this paper is an examination of the impact of qualifications and demographic characteristics on the labour-market outcome of each ethnic group. As has been widely reported, young people, women, and people without qualifications are less likely to be employed; there are variations between ethnic groups, principally the relatively high employment rates of Caribbean women and the relatively low employment rates of Pakistani and Bangladeshi women; each ethnic-minority group has lower rates of male employment than the white-Briton average, but to differing extents. Qualifications raise the employment rate of each group on average, but the impact of qualifications is less for those born outside the UK, the majority of whom will also have been educated outside the UK.

Our analysis provides new insights by applying the national relationships to interpret local labour-market outcomes. We have assessed the contribution of human capital and demographic characteristics to the geography of employment, and have distinguished them from the remaining neighbourhood effects.

We have defined and used the jobs deficit as a measure of the impact of low employment in a locality, for each ethnic group. The estimation of jobs deficits has a number of benefits. It provides expected employment outcomes to compare with observed values not only for each locality but for each subpopulation defined by age, sex, ethnic group, birthplace, and qualifications. It is based on the fully saturated model, so that each interaction of those variables with employment is fully used to assess local expected values. The jobs deficit neatly combines the size of a local population with low rates of employment in a way that can also be summed across neighbourhoods. Finally, the jobs deficit is a measure that is readily understood in relation to policy objectives aimed at equalising employment outcomes across social groups and localities.

Over 1.1 million jobs are needed to bring employment for each population in each neighbourhood up to the current England and Wales average; 1.4 million jobs would be needed to bring employment up still higher to reach the white-Briton average, for every group in every neighbourhood. For some ethnic-minority groups, jobs deficits are large relative to their population of working age - an addition of thirty percentage points to Pakistani and Bangladeshi employment, and an addition of between ten and twenty percentage points to Chinese and African employment. However, in absolute terms, half the total jobs deficit is among local white-Briton populations. The jobs deficit highlights the lack of employment amongst the white population in the same way and on the same scale as other groups.

A population's jobs deficit is greatly reduced when measured against its own average in England and Wales. Thus, local replication of national inequalities accounts for most of the total 471000 jobs deficit among nonwhite ethnic-minority groups, with a total jobs deficit of 117000 remaining. In the extreme case, the Pakistani and Bangladeshi local jobs deficits would each drop to one ninth of their current value if local employment rates were increased by the group's national deficit. This impact of national inequalities overshadows but does not eliminate the impact of local demographic composition and qualifications. The geography of qualifications, birthplace, sex, and age structure does impose further local jobs deficits for each ethnic group: many areas with low unemployment have that condition partly because their residents 
are less well qualified, or are younger than the residents of other areas. Among ethnic minorities, local deficits of 32000 jobs are accounted for in this way.

The remaining local disadvantage is not related to the measured individual characteristics of residents and is termed the neighbourhood effect. It is considerable in extent and larger than the impact of local composition measured by sex, age, qualifications, and birthplace. Its nature, however, may be structural, contextual, or compositional (Blalock, 1984; Curtis and Rees Jones, 1998). A structural economic effect might impose a lack of local jobs. A contextual effect would suggest that the local area's composition affects the employment of residents irrespective of their own characteristics. Thus, a generally low employment level may make it harder to find jobs because of poorer social networks and lower expectations of work. However, a compositional effect would simply be the concentration of individuals with poor labour-market outcomes for reasons that have not been measured. These might include selection effects: the unemployed tend to concentrate in areas of poorer housing. Thus, neighbourhood effects are not necessarily structural rather than compositional in nature, but do identify where there are particular problems faced by significant numbers of people, that are not accounted for by their level of qualifications or demographic characteristics.

We have shown that the neighbourhood effects for each ethnic group are correlated, with greater jobs deficits in neighbourhoods in the Midlands than in the South, and higher still in the northern regions of England and in Wales. Departures from that pattern involve higher local jobs deficits within the South for Chinese and in the North West for Indians, and lower jobs deficits for Pakistani and Bangladeshi groups in the North and Wales and for Africans in London. Ethnic minorities with the longest history in Britain are most integrated in its labour-market geography in the sense of greatest similarity with the white-Briton group.

The results from this paper have broad policy implications in two directions. First, neighbourhoods with large jobs deficits can be targeted for remedial action on jobs, and the focus of that action can be nuanced according to the ethnic-group composition of that jobs deficit. Second, it is clear that action to reduce inequality between ethnic groups is relevant to all neighbourhoods. Such action would require rethinking assumptions whereby, according to Webster (2006), government is often

"very confident that the problem lies entirely on the supply side of the labour market. In other words it is caused by the characteristics or motivation of workless people and not by any shortage of demand for labour" (page 107).

Our analysis confirms that the characteristics of workless people account for only a small portion of local differences in unemployment. The analysis does not provide a neat account of the causes of neighbourhood and group differences, but we can suggest some interpretations that are consistent with the results, and some questions that remain for further investigation with these and other methods.

Are the inequalities between groups due to discrimination? Quantitative evidence of direct discrimination at the point of recruitment has come from audit studies matching job applications (Esmail and Everington, 1997), while indirect discrimination has been inferred through poorer performance in the educational system (Heath and $\mathrm{Yu}, 2005$ ). Some differences in employment between ethnic groups may be chosen culturally without any sense of disadvantage necessarily attaching to them. Pakistani and Bangladeshi women's low employment could be described as partly a result of preference to nurture home and family after marriage and in particular after the birth of a child. However, only qualitative studies can identify the extent to which such a preference necessarily excludes employment, or indicates lack of employment acceptable in its location and nature (Dale et al, 2002). Such arguments of cultural preference are also not easily related to the clearly lower male employment rates for 
each ethnic minority. Our results suggest that, whatever the balance of preference and discrimination in creating ethnic inequalities, the impact is not limited to poor or ethnically diverse areas. On the contrary, those inequalities are replicated throughout England and Wales and account for most of the local jobs deficit for each ethnic minority.

What causes neighbourhood effects to vary between ethnic groups? Structural, contextual, and compositional types of neighbourhood effect might be expected to affect all groups, but the correlation between groups' neighbourhood effects is not perfect. What mechanisms might act to locally affect groups' average employment in different ways? Local agencies in their provision of services and careers support may well act differently toward each group, instilling either disadvantage or equality in different areas. Some local agencies may be specifically oriented to one or several ethnic groups, including self-help and voluntary organisations. For some individuals without English as a first language, there can be local responses which improve employment through English language support, or employment in which management is bilingual and English proficiency is unnecessary to enter the labour market in the first instance.

Finally, the categories of ethnic group are crude, as they must be in a census, and hide some variation in origins and in particular in the social and cultural networks that affect levels of employment. These variations have geographical expression, such that, for example, people from different regions of a country, or different islands of the Caribbean, will tend to live in greater numbers in different neighbourhoods, and create the neighbourhood effects we have measured. The lower employment rates of Indian Muslims relative to other Indians in Britain have been noted before (Modood et al, 1997; Peach, 2005). This may explain why the Indian jobs deficit is highest in the North West where the Muslim Indian populations are relatively large in Bolton and Preston.

We have achieved a description of the extent of ethnic-group inequalities expressed as jobs deficits, demonstrated their consistency across neighbourhoods of Britain, and developed a methodology to highlight the neighbourhoods in which employment falls most below national expectations.

Acknowledgements. The Department for Work and Pensions financed the development of the database and some of the analyses in this paper. Census data are Crown Copyright.

\section{References}

Berthoud R, 2000, "Ethnic employment penalties in Britain" Journal of Ethnic and Migration Studies $26389-416$

Bishop Y, Fienberg S, Holland P, 1975 Discrete Multivariate Analysis: Theory and Practice (MIT Press, Cambridge, MA)

Blalock H M, 1984, "Contextual-effects models: theoretical and methodological issues" Annual Review of Sociology $10353-372$

Borjas G, 1995, "Ethnicity, neighborhoods and human capital externalities" American Economic Review $85365-390$

Cabinet Office, 2003, "Ethnic minorities and the labour market", Cabinet Office, London, http://www.cabinetoffice.gov.uk/strategy/work_areas/ethnic_minorities.aspx

Carmichael F, Woods R, 2000, "Ethnic penalties in unemployment and occupational attainment: evidence for Britain" International Review of Applied Economics 1471 - 98

CCSR, 2006, "Ethnic minority populations and the labour market: analysis of the 2001 Census", Centre for Census and Survey Research, Manchester, http://asp.ccsr.ac.uk/dwp/

Cheung S Y, Heath A, 2005, "Nice work if you can get it: ethnic penalties in Great Britain", in Understanding Social Change Eds A Heath, J Ermisch, D Gallie (Oxford University Press, Oxford) pp $507-550$

Clark K, Drinkwater S, 2002, "Enclaves, neighbourhood effects and employment outcomes: ethnic minorities in England and Wales" Journal of Population Economics 15 5-29 
Clark K, Drinkwater S, 2007 Ethnic Minorities in the Labour Market: Dynamics and Diversity (Policy Press, Bristol)

Curtis, S, Rees Jones I, 1998, "Is there a place for geography in the analysis of health inequality" Sociology of Health and Illness 20 645-672

Dale A, Shaheen N, Fieldhouse E, Kalra V, 2002, "Labour market prospects for Pakistani and Bangladeshi women" Work, Employment and Society 16 5-25

Dale A, Lindley J, Dex S, 2006, "A life-course perspective on ethnic differences in women's economic activity in Britain" European Sociological Review 22 459-476

Durlauf S, 2004, "Neighborhood effects", in Handbook of Regional and Urban Economics: Volume 4. Cities and Geography Eds J Vernon Henderson, J-F Thisse (Elsevier, Amsterdam)

Esmail A, Everington S, 1997, "Asian doctors are still being discriminated against" British Medical Journal 3141619

Fieldhouse E, Tranmer M, 2001, "Concentration effects, spatial mismatch or neighbourhood selection? Exploring labour market and neighbourhood variations in male unemployment risk using census microdata from Great Britain" Geographical Analysis 33353 - 369

Heath A, Cheung S Y, 2006, "Ethnic penalties in the labour market: employers and discrimination", RR 341, Department for Work and Pensions, London, http://www.workandpensions.gov.uk/asd/ asd5/rports2005-2006/rrep341.pdf

Heath A, McMahon D, 1997, "Education and occupational attainments: the impact of ethnic origins", in Ethnicity in the 1991 Census. Volume 4: Education, Employment and Housing Ed. V Karn (The Stationery Office, London)

Heath A F, Yu S, 2005, "Explaining ethnic minority disadvantage in understanding social change", in Understanding Social Change Eds A Heath, J Ermisch, D Gallie (Oxford University Press, Oxford) pp 187-224

Leslie D, Lindley J, Thomas L, 2001, "Decline and fall: unemployment among Britain's non-white ethnic communities 1960 - 1999” Journal of the Royal Statistical Society, Series A 164371 - 387

Modood T, Berthoud R, Lakey J, Nazroo J, Smith P, Virdee S, Beishon S, 1997 Ethnic Minorities in Britain: Diversity and Disadvantage - Fourth National Survey of Ethnic Minorities (Policy Studies Institute, London)

Parkinson M, Champion T, Evans R, Simmie J, Turok I, Crookston M, Katz B, Park A, Berube A, Coombes M, Dorling D, Glass N, Hutchins M, Kearns A, Martin R, Wood P, 2006 The State of the English Cities volumes 1 and 2 (Office of the Deputy Prime Minister, London)

Peach C, 2005, "Muslims in the UK", in Muslim Britain: Communities under Pressure Ed. T Abbas (Zed Books, London) pp $18-30$

Simpson L, 2006, "Estimating local populations at risk, and expected employment outcomes", University of Manchester, http://asp.ccsr.ac.uk/dwp/info/DWP_Neighb_expectations_IPF.pdf

Simpson L, Tranmer M, 2005, "Combining sample and census data in small area estimates: iterative proportional fitting with standard software" The Professional Geographer 57222 -234

Simpson S, Purdam K, Tajar A, Fieldhouse E, Gavalas V, Tranmer M, Pritchard J, Dorling D, 2006, "Ethnic minority populations and the labour market: an analysis of the 1991 and 2001 Census", DWP Report 333, Department for Work and Pensions, London, http://asp.ccsr.ac.uk/ dwp/info/report333.pdf

Thomas B, Dorling D, 2007 People, Places and Identity (Policy Press, Bristol)

Webster D, 2006, "Welfare reform: facing up to the geographies of worklessness" Local Economy $21107-116$ 
Conditions of use. This article may be downloaded from the E\&P website for personal research by members of subscribing organisations. This PDF may not be placed on any website (or other online distribution system) without permission of the publisher. 